\title{
Renal Corpuscles Were Protected From Dichlorvos - Induced Morphological Alterations in Rats by Antioxidant Vitamins
}

\author{
Protección de Corpúsculos Renales ante Alteraciones Morfológicas Inducidas \\ por el Diclorvos en Ratas Mediante el Uso de Vitaminas Antioxidantes
}

Olatunde Owoeye"; Fabian V. Edem ${ }^{* *}$; Bukola S. Akinyoola** \& Ganiyu O. Arinola**

OWOEYE, O.; EDEM, F. V.; AKINYOOLA, B. S. \& ARINOLA, G. O. Renal corpuscles were protected from Dichlorvos-induced morphological alterations in rats by antioxidant vitamins. Int. J. Morphol., 32(2):475-480, 2014.

SUMMARY: Dichlorvos (DDVP), an organophosphorus pesticide is a volatile compound which enters the human body through oral, dermal and inhalational routes and is excreted via the kidney. This study assessed the effects of DDVP on the histology of the kidney. Twenty five male rats $(75.05 \pm 5.55 \mathrm{~g})$ were divided into 5 groups of 5 rats per group as follows: Unexposed group, exposure to DDVP alone for 5 weeks, and 3 other groups exposed to DDVP for 5 weeks in addition to supplement with Vitamin E, vitamin C, and red palm oil (RPO). Rats were exposed to DDVP in poorly ventilated cardboard cages for 4 hours daily. On completion of exposure, rats were euthanized and tissue processed by routine paraffin wax method and stained with H\&E. Morphological alterations monitored by histological and morphometric studies using the graticule and software packages. Data were analyzed with ANOVA and $\mathrm{p}<0.05$ considered as significant. DDVP caused significant reduction (10\%) in the maximum glomerular diameter and $18 \%$ reduction in the maximum width of the renal corpuscle when compared with unexposed rats. However, VTE, VTC, and RPO significantly elevated the maximum glomerular diameter by $21 \%, 22 \%, 23 \%$ the respectively. Similarly, VTE, VTC, and RPO significantly elevated the maximum width of the renal corpuscle by $17 \%, 19 \%, 20 \%$ respectfully. Glomerular tuft cellularity was neither affected by DDVP treatment nor by vitamin augmentation. Inhaled DDVP caused histological alterations in the microscopic anatomy of renal corpuscles of rat which was mitigated by vitamin supplementation. Data suggest involvement of prolonged DDVP use in the aetiology of renal failure.

KEY WORDS: Organophosphate; Pesticide; Glomerulus; Renal corpuscle; Vitamin- supplementation.

\section{INTRODUCTION}

Will prolonged exposure to pesticides freely sprayed at home or in agricultural farm-houses to kill mosquitoes and other pests lead to injury of vital organs of our bodies? This question is what this study set out to answer.

Kidney is the organ whose primary function is the maintenance of water, electrolyte and acid-base haemostasis, other functions includes the excretion and elimination of many toxic waste products among others (Young et al., 2006). Histologically, nephrons are the functional units of the kidney and are composed of renal corpuscles (glomeruli and renal corpuscle) and renal tubules. Nephrons are involved in osmoregulation and excretion through the process of ultrafiltration, selective re-absorbtion and secretion of some of the excretory substances directly from the blood into the glomerular filtrate (Mescher, 2010). Therefore, injury to the kidney will affect the function of metabolic toxic waste excretion which may affect general bodily functions if renal failure should set in.

Dichlorvos (2, 2 dichlorovinyl dimethyl phosphate) (Fig. 1), an organophosphate with strong pesticide activity (CERI, 2007). Dichlorvos (DDVP), has demonstrated alteration of the microanatomy of some internal organs of exposed mammals. Luty et al. (1998) had reported deleterious effect of DDVP on the heart, brain and other soft tissues in rats dermally exposed to DDVP. Similarly, Owoeye et al. (2012) reported development of enlarged bronchial associated lymphoid tissue in the lungs of rats chronically exposed to inhaled DDVP, as well as the necrosis and scar formation in the liver of same animals. Other reports showed alterations in the haematological parameters of rats treated with inhalational DDPV (Edem et al., 2012). In Nigeria, the ubiquitous Ota-piapia pesticide, popularly used

* Department of Anatomy, College of Medicine, University of Ibadan, Ibadan, Nigeria.

** Department of Chemical Pathology, College of Medicine, University of Ibadan, Ibadan, Nigeria. 
by low-income group has been confirmed to have dichlorvos as the preponderant active pesticide ingredient (Musa et al., 2012). The mechanism of the toxicity DDVP like other organophosphates is mainly by inhibition of acetylcholinesterases (AChE), the enzyme that decomposes acetylcholine, a major neurotransmitter of the nervous system (Harlin \& Dellinger, 1993). The consequence of the inhibition is the accumulation of acetylcholine at the various synapses thus leading to excess parasympathetic over activity which manifests as overdose symptom that may include headache, salivation, blurred vision, vomiting, etc. (CEPA, 1996). The basis for DDVP toxicity was reported to be oxidative stress through generation of reactive oxygen species (ROS) as observed in laboratory animals (WHO, 1989; Sharma \& Singh, 2012). Excess ROS production may lead to lipid peroxidation as well as damage to other macromolecules (Aruoma, 1998; Arinola et al., 2011). Expectedly, co-treatment with antioxidants can neutralize the effect of (ROS) released during such exposure thus modulating the tissue response to such an insult (Farombi et al., 2008). Vitamin E (a-tocopherol), vitamin C (ascorbic acid) and red palm oil (RPO) contain vitamins $\mathrm{E}$ and $\mathrm{A}$, have all been reported as antioxidants that are potent scavengers of ROS leading to amelioration of oxidative stress. It is anticipated that these vitamins when given as supplements will reduce the potential oxidative stress induced by DDVP (Owoeye et al., 2012). DDVP is metabolized in the liver by esterase to dimethyl phosphate and dichloroacetaldehyde; dimethyl phosphate is excreted by the kidney in the urine (CERI). The excretion of dimethyl phosphate, a waste product of DDVP for example is dependent on the integrity of the nephrons unaltered micro-anatomy; therefore, chemical injury to the kidney will affect its function. There is however, scanty literature reporting DDVP's effect on the microanatomy of the kidney.

The objective of the study is to apply histological and histo-morphometric methods in assessing the possible micro-anatomical alteration, if any, to the renal corpuscle of the kidneys after chronic DDVP vapor exposure and ameliorating effect of vitamin supplementation .

\section{MATERIAL AND METHOD}

Experimental animals and materials. This study was carried out using twenty five ten-week-old Wistar male rats $(75.05 \pm 5.55 \mathrm{~g})$ obtained from the Animal Holding facilities of Anatomy Department, University of Ibadan, Nigeria. They were acclimatized to laboratory room conditions (12 hours dark - light period) for 2 weeks before the onset of treatment. The rats were fed during the acclimatization period with rat chow from Ladokun Feeds, Ibadan, and water ad libitum. Vitamins E and C were purchased from Dana Pharmacy, Ibadan, Nigeria, while RPO was purchased from Bodija market, Ibadan. Dichlorvos was purchased from Farmers Shopping Plaza, Ogunpa, Ibadan, Nigeria. The experimental protocols were carried out according to the guidelines set by the University of Ibadan Ethical Committee, which conformed to the acceptable guidelines on the ethical use of animals in research (Public Health Service, 1996).

Research design. After the period of acclimatization, the twenty-five rats were divided into 5 equal groups using an adaptation of the method of Owoeye et al. (2012) as detailed in Figure 1. Dichlorvos (1000 mg/L) was prepared fresh daily in a dilution of 1:1 as recommended by the manufacturer (Hubei Samonda Co. Ltd, China), i.e $50 \mathrm{~mL}$ of DDVP as mixed with $50 \mathrm{~mL}$ of clean water. The groups (Table I) were separated in different cages. A poorly ventilated compartment was simulated by placing the rats in cages $(35.5 \mathrm{~cm} \times 27.5$ $\mathrm{cm} \times 19 \mathrm{~cm})$. The DDVP preparation was placed beside the cage and each cage covered with a cardboard carton with only one of the upper two lids partially opened. Rats were exposed daily to DDVP for 4 hours by this inhalational method after which the DDVP solution container and the carton were removed.

Sample collection and histological preparation. At completion of exposure, animals were anaesthetized with Ketamine anaesthesia (10 mg/kg intraperitoneally). Thereafter, left kidney of each animal was removed and fixed in $10 \%$ formalin, and dehydrated with grades of ethanol (70, 80, 90, 95 and 100\%). Dehydration was followed by clearing the samples in 2 changes of xylene. Samples were impregnated with 2 changes of molten paraffin wax, then embedded and blocked out. Paraffin sections (5-6 $\mu \mathrm{m})$ thick transverse sections of the kidney was cut using a rotary microtome (Leica RM2125RTS, Germany), and mounted on glass slides. The slides were stained with haematoxylin and eosin (H\&E) according to the method of Bancroft \& Gamble (2008).

Histology and Histomorphometry. Stained sections were examined with the light microscope (Olympus CH Japan) for histological and histomorphometric studies. Photomicrographs were taken with Sony DSC-W 30 Cybershot (Japan) at total magnification of $x 960$. In the histomorphometric measurements, 15 glomeruli and renal corpuscle (BC) on each slide of the kidney sections that were round were randomly chosen and measured in each of the groups - control and experimental. The intracapsular width of the BCs and the diameter of each of the glomeruli were measured using a graticule (Leica, Germany) with micrometer eyepiece $\mathrm{x} 10$ and objective $\mathrm{x} 40$ of the light 
microscope. The micrometer was calibrated using a slide with a customized $2 \mathrm{~mm}$ ruler engraved on a cover slip (Leica, Germany). The maximum width of each $\mathrm{BC}$ and the diameter of each selected glomerulus were measured across the minor and major axes, and the mean calculated. The glomerular tuft cellularity was estimated by counting the total number of nuclei (of mesangial and endothelial) on each glomerulus and calculating the average (Owoeye et al., 2007). Photomicrographs were further analyzed with the "line dimensions" of OpenOffice.org.Draw (Apache Software Foundation, 2013; www.openoffice.org.) for comparison of the data from the two different methods of measurements and scale bar

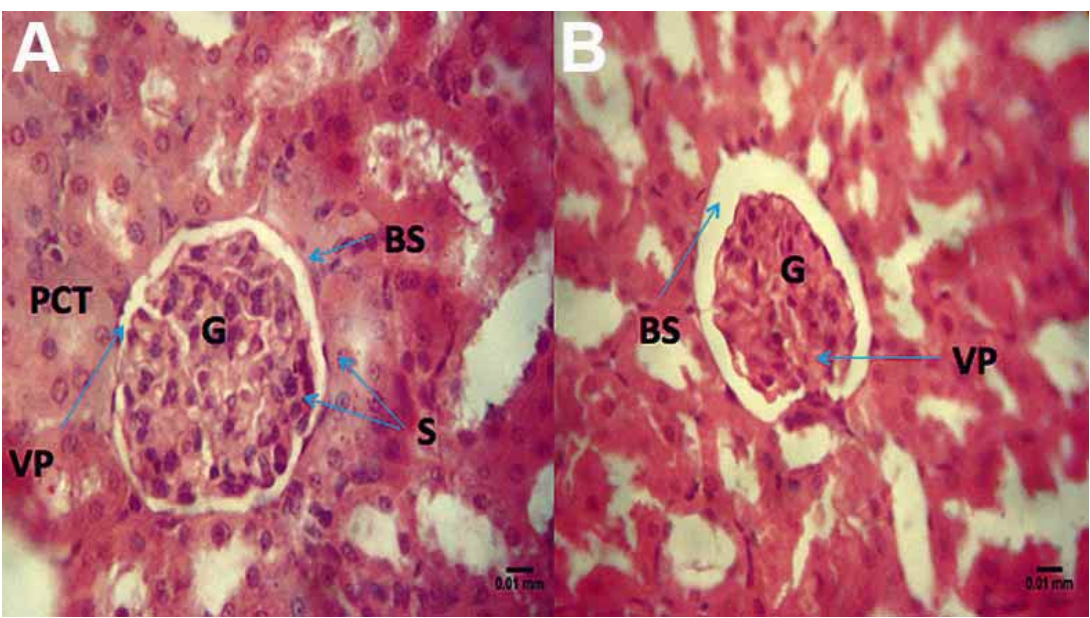

Fig. 1. Representative photomicrograph of the renal corpuscles of control, DAK (A) and DFK, rats exposed to dichlorvos for 5 weeks only (B). G, glomerulus; BS, Bowman's space; PCT, proximal convoluted tubule; $\mathrm{S}$, flattened nuclei of the squamous cells lining the BS; VP, the vascular pole that suspends the $\mathrm{G}$ within the BS. Scale bars indicate 0.01 $\mathrm{mm}(10 \mu \mathrm{m})$. BS appears wider and $\mathrm{G}$ smaller in B compared with A. using ImageJ Software. All slides were coded before examination with light microscope by two investigators who were blinded to control and treatment groups. The measurements of the dimensions were independently done by two different investigators and the means then compared to ensure consistency.

Statistical analysis. Data were expressed as Mean \pm SD. Levels of statistical significance were analyzed by one-way analysis of variance (ANOVA), followed by Student's t-test to compare the means of the experimental groups. $\mathrm{P}<0.05$ was considered statistically significant for all analyses.

Table I. Animal grouping.

\begin{tabular}{cl}
\hline Group & Treatment \\
\hline DAK & Control (unexposed $)$ \\
DFK & Exposure to DDVP alone for 5 weeks \\
DJK & Exposure to DDVP for 5 weeks plus vitamin E $(1.25 \mathrm{~g} / \mathrm{kg}$ feed per day $) ;$ \\
DKK & Exposure to DDVP for 5 weeks plus vitamin $\mathrm{C}(106 \mathrm{mg} / \mathrm{kg}$ body weight per oram per day $)$ \\
DLK & Exposure to DDVP for 5 weeks plus RPO $(2 \mathrm{~mL} / 25 \mathrm{~g}$ feed per day $)$ \\
\hline DDVP= dichlovos; $\mathrm{RPO}=$ red palm oil.
\end{tabular}

\section{RESULTS}

Microscopic anatomy of the kidney. The microanatomy of a representative renal corpuscle of the kidney of control rats is shown in Figure 1A at a magnification of x960. This photomicrograph shows a normal glomerulus and a renal corpuscle. The capsular space lined by squamous epithelium was observed. The cellularity of the glomerulus is normal. Surrounding the glomerulus are elements of the renal tubule, the proximal convoluted tubule and with its prominent cuboidal epithelium. The vascular pole that anchored the glomerulus within the capsular space was also observed to be normal. Histological observation of the photomicrographs of the representative renal corpuscle of the kidney of the experimental groups (taken at the same magnification of $\mathrm{x}$ 960 ) is shown in the other figures, namely Figures 1B, 2C, $2 \mathrm{D}, 2 \mathrm{E}$ and $2 \mathrm{~F}$ did not show obvious appreciable anomalies when compared with the control rats of Figure 1A.

Histomorphometry of the renal corpuscle of the kidney. The histomorphometry results as displayed in Table II show the significant reduction of the maximum width of renal corpuscle $(\mathrm{p}<0.05)$ of the DDVP-exposed rats when compared with unexposed group. This reduction was 
however, significantly reversed in the vitamin supplemented rats when compared with the DDVP-exposed $(<0.05)$. Similarly, Figure 2 shows that the maximal diameter of the glomeruli was significantly reduced by exposure to DDVP when compared with unexposed group. There was a significant $(\mathrm{p}<0.05)$ elevation of this parameter in the vitamin supplemented rats when compared with the DDVP-exposed rats. Glomerular tuft cellularity did not show any significant difference between the unexposed and the DDVP-exposed groups.

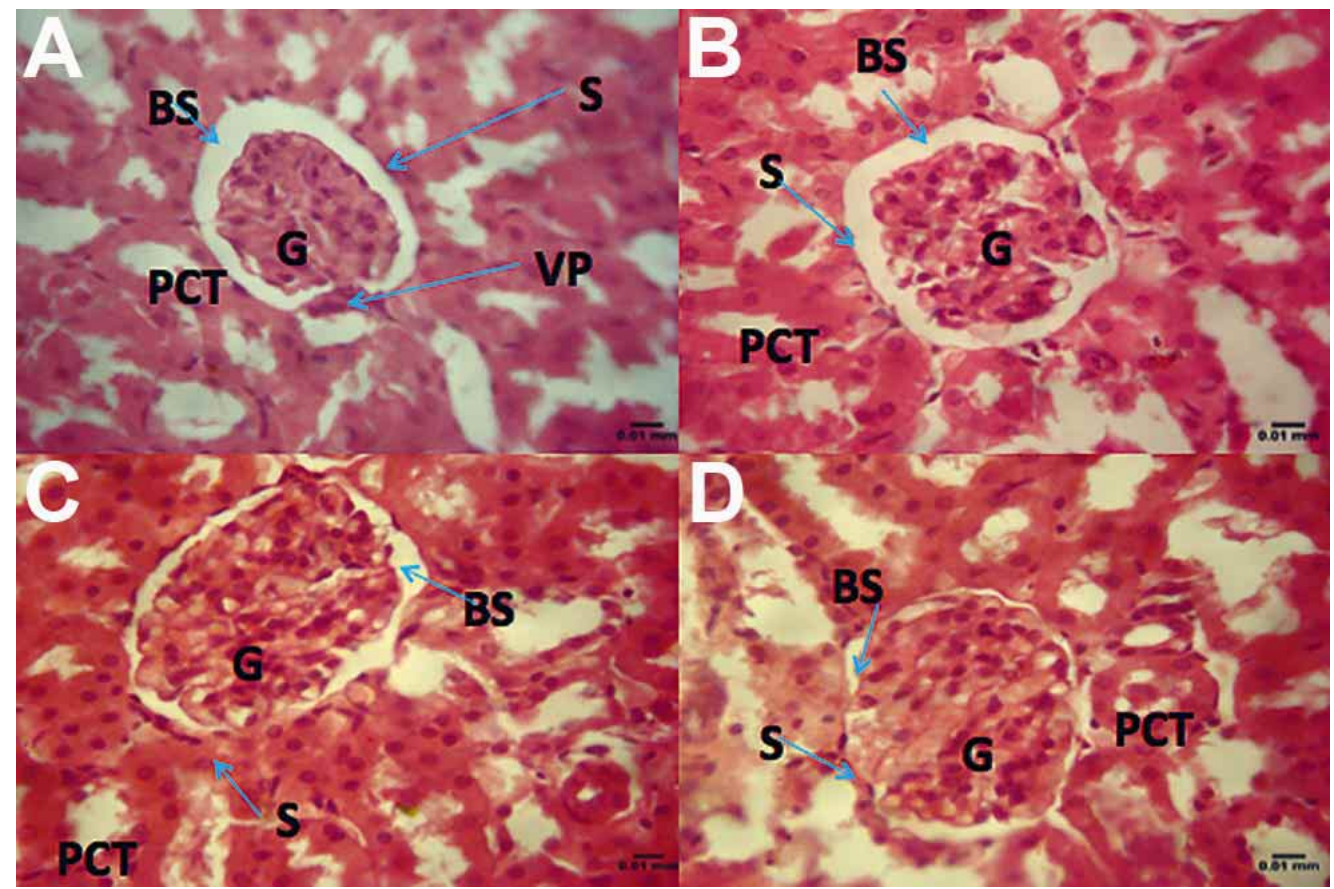

Fig. 2. Representative photomicrograph of the renal corpuscles of (A) DFK, (B) DJK, (C) DKK and (D) DLK groups. G, glomerulus; BS, Bowman's space; PCT, proximal convoluted tubule; S, flattened nuclei of the squamous cells lining the BS; VP, the vascular pole that suspends G within the BS. Scale bars indicate $0.01 \mathrm{~mm}(10 \mu \mathrm{m})$. The sizesof $\mathrm{G}$ in $\mathrm{B}, \mathrm{C}$, and D appears larger compared with $\mathrm{A}$.

Table II. Effect of vitamins E and C, and red palm oil (RPO) on the renal corpuscles of rat kidneys exposed to inhalational Dichlorvos (DDVP).

\begin{tabular}{lccc}
\hline Groups & $\begin{array}{c}\text { Maximum width of selected } \\
\text { renal corpuscle }(\boldsymbol{\mu m})\end{array}$ & $\begin{array}{c}\text { Maximum Glomerular } \\
\text { diameter }(\boldsymbol{\mu m})\end{array}$ & $\begin{array}{c}\text { Glomerular tuft } \\
\text { cellularity }(\mathbf{n o} / \boldsymbol{\mu m} 2)\end{array}$ \\
\hline DAK & $75.4 \pm 3.5$ & $60.1 \pm 3.2$ & $0.02 \pm 0.0$ \\
DFK & $61.7 \pm 5.0^{* \mathrm{c}(18.2)}$ & $49.2 \pm 3.6^{*} \mathrm{c}(10.1)$ & $0.02 \pm 0.0$ \\
DJK & $71.9 \pm 3.6^{* * \mathrm{e}(16.5)}$ & $59.6 \pm 4.2^{*} \mathrm{e}(21.1)$ & $0.02 \pm 0.0$ \\
DKK & $73.5 \pm 5.5^{* * \mathrm{e}}(18.6)$ & $60.2 \pm 5.1 * * \mathrm{e}(22)$ & $0.02 \pm 0.0$ \\
DLK & $74.1 \pm 3.1^{* *} \mathrm{e}(20.1)$ & $60.3 \pm 2.4^{*} \mathrm{e}(22.6)$ & $0.02 \pm 0.0$ \\
\hline
\end{tabular}

DAK, unexposed group; DFK, 5 weeks exposure to DDVP; DJK, 5 weeks exposure to DDVP plus vitamin E; DKK, 5 weeks exposure to DDVP plus vitamin C; DLK, 5 weeks exposure to DDVP plus red palm oil. Data are expressed as Mean \pm SD of five animals. Values in parenthesis are percentage change compared to the ccontrol and to eDFK. *: $\mathrm{P}<0.05$ versus Control; **: $\mathrm{P}<0.05$ versus DDVP only.

\section{DISCUSSION}

Our study has demonstrated quantitatively that inhalation of dichlorvos (DDVP), a pesticide commonly used in Nigeria altered the microanatomy of the renal corpuscle, a main component of the nephron. In particular, both the glomerular diameter and the width of the renal corpuscle were reduced in the rats exposed to DDVP vapor for 5 weeks. Vitamins possessing antioxidant activity significantly reversed the alteration in the renal corpuscle of the kidney. 
Functionally, the nephron is the functional unit of the mammalian kidney whose major function is the ultrafiltration of blood, removal of metabolic waste and the subsequent formation of urine among other important functions (Mescher). It is known that DDVP like other organophosphate pesticides and their metabolites are generally eliminated through urine and are likely to affect nephrons (Desai \& Desai, 2008). The glomerulus is the first part of the nephron that is directly exposed to nephrotoxins. Nephrotoxicity is the disturbance or harmful effect on the kidney mediated by drugs or other toxic substances that are exposed to the body (Klaassen \& Watkins, 2003) which is capable of inducing glomerular injury. Continuous release of dimethyl phosphate as a metabolic waste product over a period of five weeks as in this study implies continuous overloading of the kidney with dimethyl phosphate which might have injured the glomeruli. Since glomeruli consist of anastomosing network of capillaries, injury to these capillaries will lead to gross malfunction of the ultrafiltration capacity of the glomeruli.

Luty et al. (1998) had reported that both histological and ultra-structural studies of the kidney showed considerably widened spaces between the convoluted tubules infiltrated with lymphocytes, implying a possible immune reaction to the exposure to dermal DDVP for four weeks. The difference in the route and duration of administration of DDVP in their study might be responsible for the observed difference in our findings. Our findings, also did not agree with that of Blair et al. (1976), who in a similar inhalational study, reported that microscopic examinations of the DDVP toxicity could not be correlated with exposure to DDVP. Our earlier experiment indicated that tissue to exposure increases in its intensity with the duration as demonstrated in the lungs and the liver of DDVP-exposed rats (Owoeye et al., 2012).

It is conceivable that reduction of the glomeruli diameter and renal corpuscle in the DDVP-exposed rats might also be due to oxidative stress resulting from reactive oxygen species (ROS) generation by DDVP. Excessive ROS might have caused cellular damage resulting in cell shrinkage whose resultant effect was the reduction of the maximal diameter of the glomeruli and renal corpuscle. The quantitative reduction of the glomeruli and renal corpuscle dimensions in the kidneys of DDVP-exposed rats may affect glomerular function of ultrafiltration and selective reabsorption. Apart from reduction in both quantitative and qualitative performance of the kidney, retention of toxins that ought to be eliminated by the kidneys may lead to glomerular damage which may ultimately lead to renal failure as well as metabolic disturbances.
The finding that vitamins with antioxidant activities like vitamins $\mathrm{E}, \mathrm{C}$ and those present in RPO were able to ameliorate adverse effect of DDVP inhalation on kidney suggest that oxidative damage is one of the mechanisms of DDVP-induced kidney damage. The near reversal to normal histo-morphometric values in the renal corpuscles of the kidney of rats co-treated with antioxidant-containing vitamin supplements suggested that antioxidants actively reduced observed oxidative damage caused by reactive oxygen substances generated by DDVP.

We conclude from this study that inhalation of dichlorvos caused quantitative reduction of the glomeruli and renal corpuscle dimensions in the kidneys of rats; however this alteration was ameliorated with antioxidantcontaining vitamin supplementation. Immunohistochemical and ultrastructural investigations are needed to correlate these findings with potential threat posed by chronic exposure to dichlorvos as a pesticide used in pest control especially in enclosed areas. It is recommended that those who work with or handle dichlorvos should take prudent steps to reduce duration of exposures as long-term exposure may lead to renal failure in future.

OWOEYE, O.; EDEM, F. V.; AKINYOOLA, B. S. \& ARINOLA, G. O. Protección de corpúsculos renales ante alteraciones morfológicas inducidas por el diclorvos en ratas mediante el uso de vitaminas antioxidantes. Int. J. Morphol., 32(2):475480, 2014.

RESUMEN: El diclorvos (DDVP), un pesticidas organofosforado, es un compuesto volátil que entra en el cuerpo humano a través de la vía oral, dérmica y por rutas inhalación, excretándose por vía renal. Este estudio evaluó los efectos histológicos del DDVP sobre el riñón. Veinticinco ratas machos $(75,05 \pm 5,55 \mathrm{~g})$ se dividieron en 5 grupos de 5 ratas cada uno: grupo no expuesto, expuesto a DDVP durante 5 semanas, y otros 3 grupos expuestos a DDVP durante 5 semanas, suplementados con vitamina E (VTE), vitamina C (VTC) y aceite de palma roja (APR). Las ratas fueron expuestas a DDVP en jaulas de cartón con poca ventilación por 4 horas diarias. Al término de la exposición, las ratas se sacrificaron y el tejido fue procesado para inclusión en parafina y tinción con H\&E. Las alteraciones morfológicas se evaluaron mediante estudios histológicos y morfométricos utilizando retículas y software. Los datos se analizaron con la prueba ANOVA considerado un $\mathrm{p}<0,05$ como significativo. El DDVP causó una reducción significativa (10\%) en el diámetro máximo glomerular y ancho máximo del copúsculo renal (18\%), en comparación con las ratas no expuestas. Sin embargo, el diámetro máximo glomerular fue significativamente elevado con VTE, VTC y APR en $21 \%$, $22 \%$ y $23 \%$, respectivamente, así como para el ancho máximo del corpúsculo renal por $17 \%, 19 \%$ y $20 \%$, respectivamente. La celularidad de la red glomerular no fue afectada por el DDVP ni aumentó con el tratamiento de vitamina. El DDVP inhalado provocó alteraciones histológicas en la anatomía microscópica de los 
corpúsculos renales de rata, las que fueron mitigadas por la suplementación de vitamina. Los datos sugieren relación entre la exposición prolongada a DDVP y la etiología de la insuficiencia renal.

PALABRAS CLAVE: Organofosforados; Plaguicidas; Glomérulo; Corpúsculo renal; Suplementos de vitamina.

\section{REFERENCES}

Arinola, O. G.; Akinosun, O. M. \& Olaniyi, J. A. Passive and active cigarette smoking: effects on the levels of antioxidant vitamins, immunoglobulin classes and acute phase reactants. Afr. J. Biotechnol., 10(32):6130-2, 2011.

Aruoma, O. I. Free radicals, oxidative stress, and antioxidants in human health and disease. J. Am. Oil Chem. Soc., 75(2):199212, 1998.

Bancroft, J. D. \& Gamble, M. Theory and Practice of Histology Techniques. $6^{\text {th }}$ ed. Philadelphia, Churchill Livingstone Elsevier, 2008. pp.83-134.

Blair, D.; Dix, K. M.; Hunt, P. F.; Thorpe, E.; Stevenson, D. E. \& Walker, A. I. Dichlorvos: a 2-year inhalation carcinogenesis study. Arch. Toxicol., 35(4):281-94, 1976.

California Environmental Protection Agency (CEPA). Dichlorvos (DDVP) Risk Characterization Document, Medical Toxicology and Worker Health and Safety Branches Department of Pesticide Regulation California. Environmental Protection Agency. California, CEPA USA, 1996. pp.1-119.

Chemicals Evaluation and Research Institute (CERI). Japan Hazard assessment report on Dimethyl 2,2-dichlorovinyl phosphate. CAS no. 62-73-7, 2007.

Desai, S. N. \& Desai, P. V. Changes in renal clearance and renal tubular function in albino mice under the influence of Dichlorvos. Pestic. Biochem. Physiol., 91(3):160-9, 2008.

Edem, V. F.; Akinyoola, S. B.; Olaniyi, J. A.; Rahaman. S. K.; Owoeye, S. K. \& Arinola, O. G. Haematological parameters of Wistar rats exposed to 2, 2 dichlorovinyl dimethyl phosphate chemical. Asian J. Exp. Biol. Sci., 3(4):838-41, 2012.

Farombi, E. O.; Ugwuezunmba, M. C.; Ezenwadu, T. T.; Oyeyemi, M. O. \& Ekor, M. Tetracycline-induced reproductive toxicity in male rats: effects of vitamin $\mathrm{C}$ and $\mathrm{N}$-acetylcysteine. Exp. Toxicol. Pathol., 60(1):77-85, 2008

Harlin, K. S. \& Dellinger, J. A. Retina, brain and blood cholinesterase levels in cats treated with oral dichlorvos. Vet. Hum. Toxicol., 35(3):201-3, 1993.
Klaassen, C. \& Watkins, J. Essentials of Toxicology. New York, McGraw-Hill, 2003. pp.213-4.

Luty, S.; Latuszynska, J.; Halliop, J.; Tochman, A.; Obuchowska, D.; Przylepa, E.; Korczak, E. \& Bychawski, E. Toxicity of dermally absorbed dichlorvos in rats. Ann. Agric. Environ. Med., 5(1):57-64, 1998.

Mescher, A. L. Junqueira's Basic Histology, Text and Atlas. 12 $2^{\text {th }}$ ed. New York, McGraw Hill Lange, 2010. pp.287-97.

Musa, U.; Hati, S. S.; Mustapha, A. \& Magaji, G. Dichlorvos concentrations in locally formulated pesticide (Ota-piapia) utilized in northeastern Nigeria. Sci. Res. Essay, 5(1):49-54, 2010 .

Owoeye, O.; Edem, F. V.; Akinyoola, B. S.; Rahaman, S.; Akang, E. E. \& Arinola, G. O. Histological changes in liver and lungs of rats exposed to dichlorvos before and after vitamin supplementation. Eur. J. Anat., 16(3):190-8, 2012.

Owoeye, O.; Malomo, A. O.; Elumelu, T. N.; Salami, A. A.; Osuagwu, F. C.; Akinlolu, A. A.; Adenipekun, A. \& Shokunbi, M. T. Radiation Nephritis: anti-inflammatory effect of dexamethasone in adult Wistar rats (Rattus novegicus). Int. J. Morphol., 26(1):69-74, 2007.

Public Health Service (PHS). Public health service policy on humane care and use of laboratory animals. Washington DC, US Department of Health and Human Services, 1996. pp.99158.

Sharma, P. \& Singh, R. Dichlorvos and lindane induced oxidative stress in rat brain: Protective effects of ginger. Pharmacognosy Res., 4(1):27-32, 2012.

World Health Organization (WHO). Environmental health criteria. Dichlorvos. Geneva, World Health Organizatio, 1989.

Young, B.; Lowe, J. S.; Smith, A. \& Heath, J. W. Wheater's Functional Histology. A text and colour Atlas. $5^{\text {th }}$ ed. Philadelphia, Churchill Livingstone, Elsevier, 2006. pp.30227.

Correspondence to:

Dr. Olatunde Owoeye.

Department of Anatomy

College of Medicine

University of Ibadan

Ibadan

NIGERIA

Email: oowoeye2001@yahoo.com o.owoeye@mail.ui.edu.ng

Received: 17-11-2013

Accepted: 11-04-2014 